\title{
PREDIKSI LUAS AREA KEBAKARAN HUTAN BERDASARKAN DATA METEOROLOGI DENGAN MENGGUNAKAN PENDEKATAN MULTIVARIATE ADAPTIVE REGRESSION SPLINES (MARS)
}

\author{
Winalia Agwil ${ }^{1}$, Izzati Rahmi $\mathrm{HG}^{2}$, Hazmira Yozza ${ }^{2}$ \\ Program Studi Matematika, \\ Fakultas Matematika dan Ilmu Pengetahuan Alam, Universitas Andalas Padang, \\ Kampus UNAND Limau Manis Padang, Indonesia \\ wina_chou@ymail.com,izzatirahmihg@yahoo.com,hyozza@gmail.com
}

\begin{abstract}
Abstrak. Luas area kebakaran hutan dapat diduga berdasarkan data meteorologi antara lain koordinat sumbu $x$ spasial suatu lokasi dalam peta, koordinat sumbu $y$ spasial suatu lokasi dalam peta, bulan, hari, indeks FFMC, indeks DMC, indeks DC, indeks ISI, temperatur, kelembaban relatif, kecepatan angin dan curah hujan. Pendugaan terhadap luas area kebakaran hutan dapat diduga dengan menggunakan pendekatan Multivariate Adaptive Regression Spline(MARS). Data yang digunakan adalah data meteorologi wilayah Portugal. Hasil pendugaan luas area kebakaran hutan dengan menggunakan MARS menghasilkan beberapa variabel yang berpengaruh secara signifikan yaitu : FFMC, hari, temperatur, DMC, kelembaban relatif, bulan, koordinat sumbu $y$ spasial suatu lokasi dalam peta, DC, dan koordinat sumbu $x$ spasial suatu lokasi dalam peta dengan tingkat kepentingan berturut-turut 100\%, 90.9\%, 73.5\%, $34.5 \%, 25,1 \%, 23.1 \%, 19.6 \%, 17.9 \%$ dan $5.7 \%$.

Kata kunci: Kebakaran Hutan, Data Meteorologi, Multivariate Adaptive Regression Spline (MARS).
\end{abstract}

\section{Pendahuluan}

Hutan merupakan salah satu sumber daya alam yang memiliki peran penting dan bermanfaat bagi manusia. Kebakaran hutan adalah kebakaran yang terjadi dalam kawasan hutan baik disengaja maupun tanpa disengaja. Terjadinya kebakaran hutan akibat faktor kesengajaan manusia terjadi pada beberapa kegiatan seperti kegiatan ladang, PIR (Perkebunan Inti Rakyat), HTI (Hutan Tanaman Industri) dan penyiapan lahan untuk ternak sapi. Sekitar 90\% kejadian kebakaran hutan disebabkan karena kurangnya pengawasan dalam melakukan kegiatan-kegiatan tersebut. Kebakaran hutan juga bisa disebabkan oleh faktor ketidaksengajaan yang disebabkan oleh faktor alami ataupun karena kelalaian manusia.

Melihat tingginya angka kejadian kebakaran hutan pada saat ini, banyak peneliti kebakaran hutan mencari cara untuk menanggulanginya. Salah satunya adalah dengan menerapkan Fire Danger Rating System(FDRS) yaitu suatu sistem yang dikembangkan di Kanada untuk menentukan peringkat bahaya kebakaran regional. Subsistem dari Fire Danger Rating System adalah FWI (Fire 
Weather Index) atau indeks cuaca kebakaran yang berguna untuk melihat pengaruh cuaca terhadap kelembaban bahan bakar dan perilaku kebakaran, selain itu juga untuk melihat intensitas laju kebakaran dan ketersediaan bahan bakar.

Berdasarkan indeks-indeks pada sistem FWI beserta data meteorologi lainnya seperti kelembaban relatif, curah hujan, temperatur dan kecepatan angin, dapat diprediksikan kemungkinan luasnya area kebakaran hutan di suatu lokasi tertentu. Prediksi ini sangat penting agar dapat dilakukan antisipasi terhadap dampak kebakaran hutan tersebut. Salah satu pendekatan yang dapat dilakukan untuk memodelkan luas area kebakaran hutan adalah MARS (Multivariate Adaptive Regression Splines). MARS (Multivariate Adaptive Regression Splines) merupakan pendekatan regresi nonparametrik yang menghasilkan pemodelan regresi yang fleksibel untuk data dengan variabel prediktor $3 \leq k \leq 20$ dan ukuran contoh $50 \leq \mathrm{n} \leq 1000$. Model MARS merupakan perluasan hasil kali fungsi basis spline, dimana jumlah fungsi basis beserta parameter parameternya (derajat hasil kali, lokasi knot) ditentukan oleh data dengan menggunakan algoritma recursive partitioning yang dimodifikasi.

\section{MARS (Multivariate Adaptive Regression Spline)}

Pada tahun 1990, Jerome H. Friedman memperkenalkan metode MARS sebagai suatu metode baru yang mengotomatiskan pembangunan model-model prediktif akurat untuk variabel-variabel respon kontinu dan biner. Model MARS difokuskan untuk mengatasi permasalahan dimensi yang tinggi dan diskontiouitas pada data. MARS merupakan pengembangan dari pendekatan Recursive Partition Regression (RPR) yang menghasilkan model yang tidak kontinu pada $\operatorname{knot}[4]$.

Beberapa hal yang perlu diperhatikan dalam membangun model MARS yaitu:

a. Knot, merupakan nilai variabel prediktor ketika slope suatu garis regresi mengalami perubahan yang dapat didefinisikan sebagai akhir dari satu segmen sekaligus merupakan awal dari segmen yang lain. Di setiap titik knot, diharapkan adanya kontinuitas dari fungsi basis antar satu region dengan region lainnya. Minimum observasi antara knot (MO) adalah $0,1,2$, dan 3 observasi.

b. Fungsi basis $(B)$ yaitu selang antar knot yang berurutan. Pada umumnya fungsi basis yang dipilih berbentuk polinomial dengan turunan yang kontinu pada setiap titik knot. Maksimum fungsi basis yang diijinkan adalah 2-4 kali jumlah variabel prediktornya.

c. Interaction (interaksi) yaitu hasil perkalian silang antar variabel yang saling berkorelasi. Jumlah maksimum interaksi (MI) yang diperbolehkan adalah 1, 2, atau 3. Jika $M I>3$ akan dihasilkan model yang semakin kompleks dan model akan sulit untuk diinterpretasi.

Model MARS adalah sebagai berikut :

$$
f(x)=a_{0}+\sum_{m=1}^{M} a_{m} \prod_{k=1}^{k_{m}}\left(S_{k m}\left(X_{V(k, m)}-t_{k m}\right)\right)+,
$$

dengan

$a_{0} \quad$ : konstanta regresi dari fungsi basis 


$$
\begin{aligned}
& a_{m} \quad: \text { koefisien dari fungsi basis ke- } m, m=1, \cdots, M \\
& M \quad \text { : maksimum fungsi basis (nonconstant fungsi basis) } \\
& \text { km : derajat interaksi } \\
& S_{k m}:\left\{\begin{array}{l}
+1, \text { jika knot terletak dikanan subregion } \\
-1, \text { jika knot terletak dikiri subregion }
\end{array}\right. \\
& X_{v(k, m)} \text { : variabel prediktor } \\
& t_{k m} \quad \text { : nilai knots dari variabel prediktor } X_{v}(k, m) \text {. }
\end{aligned}
$$

Koefisien $\left\{a_{m}\right\}_{m=1}^{M}$ ditentukan dengan metode kuadrat terkecil. Model MARS juga dapat ditulis dalam bentuk sebagai berikut :

$$
\hat{f}_{x}=\alpha_{0}+\alpha_{1} B_{1}+\alpha_{2} B_{2}+\alpha_{3} B_{3}+\cdots+\alpha_{M} B_{M}
$$

Pemilihan knots pada MARS menggunakan algoritma forward stepwise dan backward stepwise. Adapun langkah dalam forward stepwise[5] :

(a) Misalkan $B_{0}=1$ sebagai fungsi basis awal.

(b) Tentukan pasangan fungsi basis $B_{1}=\left(x_{i}-t\right)_{+}$dan $B_{2}=\left(t-x_{i}\right)_{+}$yang merupakan kombinasi prediktor $x_{i}$ dan knot $t_{1}$ sehingga model

$$
y=\alpha_{0}+\alpha_{1} B_{1}+\alpha_{2} B_{2}
$$

memiliki jumlah kuadrat sisaan minimum. $\alpha_{0}, \alpha_{1}$ dan $\alpha_{2}$ diduga dari metode kuadrat terkecil.

(c) Misalkan $B_{m}$ adalah salah satu fungsi basis yang sudah ada didalam model sebelumnya. Jika $m$ fungsi basis telah dimasukkan, tentukan perkalian dari $B_{m}$ dengan $\left(x_{m}-t\right)_{+}$atau $\left(t-x_{m}\right)_{+}$sehingga jika $B_{m}\left(t-x_{m}\right)_{+}$dan $B_{m}\left(x_{m}-t\right)_{+}$ditambahkan ke dalam model maka akan dihasilkan model dengan jumlah kuadrat sisaan terkecil.

(d) Ulangi langkah (c) sehingga banyaknya fungsi basis dalam model lebih atau sama dengan maksimum banyaknya fungsi basis yang telah ditetapkan.

Setelah diperoleh model dari langkah forward stepwise kemudian dilanjutkan dengan langkah backward stepwise yaitu :

(a) Mulai dari model yang diperoleh pada tahap prosedur forward yang memiliki $M$ fungsi basis.

(b) Hapus salah satu fungsi basis tidak konstan yang memiliki kontribusi terkecil. Berdasarkan kriteria kuadrat terkecil, fungsi basis yang memiliki kontribusi terkecil adalah fungsi basis yang jika dihilangkan dari model sebelumnya akan menyebabkan terjadinya kenaikan jumlah kuadrat sisaan terkecil.

(c) Ulangi langkah (b), sampai model hanya mengandung fungsi basis konstan.

Prosedur backward ini menghasilkan sekuens model yang tersarang, $f_{m}$ $(m=1,2, \cdots)$. Model terbaik ditentukan berdasarkan kriteria Generalized Cross Vali-dation (GCV) yang diperkenalkan oleh Wahba pada tahun 1979. Fungsi GCV didefinisikan sebagai berikut :

$$
G C V(M)=\frac{1 / N \sum_{i=1}^{N}\left[y_{i}-\hat{f}_{M}\left(x_{i}\right)\right]^{2}}{[1-(C(M)) / N]^{2}}
$$

dengan

$M \quad$ : jumlah fungsi basis 
$x_{i} \quad:$ variabel prediktor

$y_{i} \quad$ : variabel respon

$N \quad$ : banyaknya pengamatan

$C(M):$ Trace $\left[\boldsymbol{B}\left(\boldsymbol{B}^{T} \boldsymbol{B}\right)^{-1} \boldsymbol{B}^{T}\right]+1$

Pada model MARS dilakukan uji signifikansi fungsi basis yang meliputi uji bersamaan dan uji individu. Uji signifikansi yang dilakukan secara bersamaan/serentak terhadap fungsi basis-fungsi basis yang terdapat dalam model MARS ini bertujuan untuk mengetahui apakah secara umum model MARS terpilih merupakan model yang sesuai dan menunjukkan hubungan yang tepat antara variabel prediktor dengan variabel respon. Hipotesis yang digunakan adalah:

$H_{0}: \alpha_{1}=\alpha_{2}=\cdots=\alpha_{m}=0$

$H_{1}:$ ada $\alpha_{j} \neq 0, j=1,2, \cdots, m$

Hipotesis nol $H_{0}$ akan ditolak jika $F_{\text {hitung }}>F_{\alpha\left(v_{1}, v_{2}\right)}$ artinya tidak terdapat pengaruh fungsi basis terhadap model. Nilai $F_{\alpha\left(v_{1}, v_{2}\right)}$ diperoleh dari tingkat signifikansi $\alpha$ serta $v_{1}=k$ dan $v_{2}=n-k-1$ dengan $n$ adalah banyaknya sampel dan $k$ adalah banyaknya fungsi basis yang berkontribusi terhadap model. Nilai $F_{\text {hitung }}$ diperoleh dari perhitungan berikut

$$
F_{\text {hitung }}=\frac{\sum_{i=1}^{n}\left(\hat{y}_{l}-\bar{y}\right)^{2} / k}{\sum_{i=1}^{n}\left(y_{i}-\hat{y}_{l}\right)^{2} / n-k-1} .
$$

Kemudian akan dilakukan pengujian untuk masing - masing fungsi basis yang bertujuan untuk mengetahui apakah fungsi basis yang terbentuk mempunyai pengaruh signifikan terhadap model, selain itu ingin diketahui pula apakah model yang memuat parameter tersebut telah mampu menggambarkan keadaan data yang sebenarnya. Hipotesisnya adalah sebagai berikut :

$H_{0}: \alpha_{j}=0$

$H_{1}: \alpha_{j} \neq 0, j=1,2, \cdots, m$

Hipotesis nol $H_{0}$ akan ditolak jika $t_{\text {hitung }}>t_{\left(\frac{\alpha}{2}, v_{2}\right)}$ artinya tidak terdapat pengaruh variabel prediktor terhadap variabel respon pada fungsi basis ke- $j$ di dalam model. Nilai $t_{\left(\frac{\alpha}{2}, v_{2}\right)}$ diperoleh dengan derajat bebas $v_{2}=k$ dan tingkat signifikansi dan nilai $t_{\text {hitung }}$ diperoleh dari

$$
t_{\text {hitung }}=\frac{\alpha_{j}}{s_{a_{j}}}
$$

dengan $s_{\alpha_{j}}$ merupakan standar error $\alpha_{j}$ yang diperoleh dari

$$
s_{\alpha_{j}}=\sqrt{\left(\frac{\sum_{i=1}^{n}\left(y_{i}-\hat{y}_{l}\right)^{2}}{n-k-1}\right) C_{j j}},
$$

$C_{j j}$ adalah elemen-elemen pada diagonal utama matriks $\left(\mathbf{B}^{T} \mathbf{B}\right)^{-1}$

\section{Metodologi Penelitian}

Data yang digunakan pada penelitian ini adalah data sekunder yang diperoleh dari penelitian P. Cortez and A. Morais tentang kebakaran hutan 200 lokasi di wilayah Portugal. Data diperoleh dari [1]. 
Variabel respon $Y$ menunjukkan luas area kebakaran dalam hektar (Ha). Kemudian variabel $X$ dipilih berdasarkan informasi dari penelitian sebelumnya tentang faktor yang menyebabkan kejadian kebakaran hutan. Adapun variabel prediktor sebagai berikut:

$X_{1}$ : Koordinat sumbu $x$ spasial suatu lokasi dalam peta. Variabel ini memiliki nilai mulai dari 1 sampai 10.

$X_{2}$ : Koordinat sumbu $y$ spasial suatu lokasi dalam peta. Variabel ini memiliki nilai mulai dari 1 sampai 10.

$X_{3}$ : Bulan kebakaran hutan. Variabel bulan memiliki skala nominal dengan 12 kategori (1 jika Januari, 2 jika Februari, 3 jika Maret, 4 jika April, 5 jika Mei, 6 jika Juni, 7 jika Juli, 8 jika Agustus, 9 jika September, 10 jika Oktober, 11 jika November dan 12 jika Desember).

$X_{4}$ : Hari terjadinya kebakaran hutan. Variabel hari memiliki skala nominal dengan 7 kategori (1 jika Senin, 2 jika Selasa, 3 jika Rabu, 4 jika Kamis, 5 jika Jumat, 6 jika Sabtu dan 7 jika Minggu).

$X_{5}$ : Indeks kelembaban bahan bakar halus atau Fine Fuel Moisture Code (FFMC). FFMC memiliki nilai mulai dari $18.7 \mathrm{~s} / \mathrm{d} 96.20$.

$X_{6}$ : Angka peringkat rata-rata kadar air dari bahan organik permukaan atau Duff Moisture Code (DMC). DMC memiliki nilai mulai dari $1.1 \mathrm{~s} / \mathrm{d}$ 291.3.

$X_{7}$ : Angka peringkat rata-rata kadar air dari bahan organik dibawah permukaan atau Drought Code (DC). DC memiliki nilai mulai dari $7.9 \mathrm{~s} / \mathrm{d} 860.6$.

$X_{8}$ : Angka peringkat dari dugaan/harapan kecepatan api atau Initial Spread Index (ISI). ISI memiliki nilai mulai dari $0.0 \mathrm{~s} / \mathrm{d} 56.1$.

$X_{9}$ : Temperatur (dalam Celcius) yang bernilai dari $2.2 \mathrm{~s} / \mathrm{d} 33.3$.

$X_{10}$ : Kelembaban relatif (dalam \%). Kelembaban memiliki nilai mulai dari $15 \mathrm{~s} / \mathrm{d}$ 100.

$X_{11}$ : Kecepatan angin (dalam $\left.\mathrm{km} / \mathrm{jam}\right)$. Kecepatan angin memiliki nilai mulai dari $0.4 \mathrm{~s} / \mathrm{d} 9.4$.

$X_{12}$ : Curah hujan (dalam $\mathrm{mm} / \mathrm{m} 2$ ) yang memiliki nilai dari $0.0 \mathrm{~s} / \mathrm{d}$ 6.4.

Adapun langkah-langkah dalam penelitian ini adalah

a. Mengkombinasikan besarnya basis function (B), Maximum Interaction (MI) dan Minimum Observation (MO) pada data yang digunakan dengan cara:

- Menentukan kemungkinan maksimum banyaknya basis function (B) yaitu 2-4 kali jumlah prediktor yang akan digunakan. Kemungkinan maksimum banyaknya fungsi basis pada penelitian ini adalah 24, 36 dan 48.

- Menentukan jumlah maksimum interaksi (Max-I), yaitu 1,2 dan 3.

- Menentukan minimal jumlah pengamatan setiap knots (Min-O), yaitu $0,1,2$ dan 3 .

b. Menetapkan model terbaik dengan didasarkan pada nilai $G C V$ minimum yang diperoleh dengan mengkombinasikan maksimum $B, M I$, dan $M O$.

c. Menduga koefisien model $\left(\alpha_{0}, \alpha_{1}, \cdots, \alpha_{m}\right)$. Model MARS yang diperoleh adalah sebagai berikut:

$$
\hat{f}_{x}=\alpha_{0}+\alpha_{1} B_{1}+\alpha_{2} B_{2}+\alpha_{3} B_{3}+\cdots+\alpha_{M} B_{M}
$$

$\hat{f}_{x}$ merupakan luas area kebakaran hutan, $\alpha_{0}$ adalah konstanta, $\alpha_{m}$ adalah koefisien fungsi basis ke- $m$ sedangkan $B_{m}$ merupakan fungsi basis ke- $m$.

d. Mengelompokkan fungsi basis berdasarkan variabel prediktor yang masuk dalam model. 
e. Menginterpretasikan tingkat kontribusi dan pengurangan $G C V$ variabel yang mempunyai kepentingan dalam pengelompokan variabel respon.

f. Menguji keakurasian prediksi model MARS yang terbentuk dari data, uji dilakukan secara bersamaan dan individual pada setiap fungsi basis.

\section{Analisis Dan Pembahasan}

Model terbaik pada model MARS adalah model dengan nilai $G C V$ paling kecil. Berdasarkan kombinasi fungsi basis 24, 36 dan 48 dengan maksimum interaksi 1, 2 atau 3 dan minimum observasi 0, 1, 2 dan 3, GCV paling kecil diperoleh jika digunakan maksimum $B=36, M I=3$ dan $M O=1$ yaitu $G C V=559,61529$ dan $R^{2}=0.95759$, dimana jumlah variabel prediktor yang signifikan mempengaruhi model sebanyak 9 dari 12 variabel prediktor.

$$
\begin{gathered}
Y=7.7048-3584.89 B_{3}+2473.69 B_{5}+38.6398 B_{7}-692.119 B_{8} \\
+10.8058 B_{9}+38.6108 B_{10}-39.9882 B_{11}+16.5518 B_{15} \\
+80.9686 B_{18}-3.84012 B_{21}-0.164255 B_{22}+0.203328 B_{23} \\
+4.29203 B_{24}+2.42603 B_{25}+1.23225 B_{27}+41.4178 B_{29} \\
+9.3096 B_{31}-88.1878 B 35
\end{gathered}
$$

dengan

$$
\begin{array}{ll}
B_{1}=\left(X_{4}=6\right) & B_{18}=\max \left(0,3-X_{2}\right) B_{13} \\
B_{2}=\left(X_{4}=1,2,3,4,5,7\right) & B_{21}=\max \left(0, X_{7}-601.4\right) B_{13} \\
B_{3}=\max \left(0, X_{5}-92.5\right) B_{1} & B_{22}=\max \left(0,601.4-X_{7}\right) B_{13} \\
B_{5}=\max \left(0, X_{5}-92.2\right) B_{1} & B_{23}=\max \left(0, X_{6}-32.8\right) B_{13} \\
B_{7}=\max \left(0, X_{9}-21.4\right) B_{5} & B_{24}=\max \left(0,32.8 X_{6}\right) B_{13} \\
B_{8}=\max \left(0,21.4-X_{9}\right) B_{5} & B_{25}=\max \left(0, X_{7}-664.2\right) B_{13} \\
B_{9}=\max \left(0, X_{6}-145.4\right) B_{5} & B_{27}=\max \left(0, X_{7}-466.3\right) B_{13} \\
B_{10}=\max \left(0,145.4-X_{6}\right) B_{5} & B_{29}=\max \left(0, X_{1}-8\right) B_{2} \\
B_{11}=\max \left(0, X_{10}-31\right) B_{5} & B_{31}=\max \left(0, X_{2}-3\right) B_{1} \\
B_{13}=\left(X_{3}=7,9,10,2\right) B_{2} & B_{35}=\max \left(0, X_{5}-92.5\right) B_{3} \\
B_{15}=\max \left(0, X_{9}-23.9\right) B_{13} &
\end{array}
$$

Interpretasi dari koefisien-koefisien fungsi basis pada model MARS diatas adalah :

$B_{3}=\max (0, \mathrm{X} 5-92.5) \mathrm{B} 1$ dengan koefisien -3584.89 : Luas area kebakaran hutan di daerah dengan $F F M C>92.5$ pada hari sabtu akan berkurang sebesar 3584,89 Ha bila nilai B3 naik sebesar 1 satuan.

$B_{5}=\max (0, \mathrm{X} 5-92.2)$ B1 dengan koefisien $2473.69:$ Luas area kebakaran hutan di daerah dengan $F F M C>92.2$ pada hari sabtu akan bertambah sebesar 2473,69 Ha bila nilai B5 naik sebesar 1 satuan.

$B_{7}=\max (0, \mathrm{X} 9-21.4)$ B5 dengan koefisien $38.6398:$ Luas area kebakaran hutan di daerah dengan $F F M C>92.2$ dan temperatur $>21.4$ pada hari sabtu akan bertambah sebesar $38.64 \mathrm{Ha}$ bila nilai B7 naik sebesar 1 satuan. 
$B_{8}=\max (0,21.4-X 9)$ B5 dengan koefisien -692.119 : Luas area kebakaran hutan di daerah dengan $F F M C>92.2$ dan temperatur $<21.4$ pada hari sabtu akan berkurang sebesar 692.12 Ha bila nilai B8 naik sebesar 1 satuan.

$B_{9}=\max (0, \mathrm{X} 6-145.4)$ B5 dengan koefisien 10.8058: Luas area kebakaran hutan di daerah dengan $F F M C>92.2$ dan $D M C>145.4$ pada hari sabtu akan bertambah sebesar 10.81 Ha bila nilai B9 naik sebesar 1 satuan.

Demikian seterusnya untuk interpretasi fungsi basis lainnya.

Pada model MARS yang telah diperoleh dilakukan uji signifikansi yang meliputi uji fungsi basis secara keseluruhan (secara serempak/bersama) dan uji masing-masing fungsi basis. Uji signifikansi (keberartian) yang dilakukan secara bersamaan untuk fungsi basis-fungsi basis yang terdapat pada model MARS menggunakan hipotesis sebagai berikut :

$H_{0}: \alpha_{3}=\alpha_{5}=\alpha_{7}=\alpha_{8}=\alpha_{10}=\alpha_{11}=\alpha_{15}=\alpha_{18}=\alpha_{21}=\alpha_{22}=\alpha_{23}=\alpha_{24}=$
$\alpha_{25}=\alpha_{27}=\alpha_{29}=\alpha_{31}=\alpha_{35}=0$
$H_{1}: \alpha_{j} \neq 0, j=3,5,7,8,9,10,11,15,18,21,22,23,24,25,27,29,31$ dan 35

Berdasarkan hasil pengolahan MARS diperoleh nilai $F_{\text {hitung }}=209,99131$. Dengan $\alpha=0,05$, nilai $v_{1}=18$ dan $v_{2}=181$ diperoleh nilai $F_{0.05(18,181)}=1,57$, karena $F_{\text {hitung }}>1,57$ maka keputusan yang diambil adalah menolak $H_{0}$ yang berarti terdapat paling tidak satu $\alpha_{j}$ yang tidak sama dengan nol atau dengan kata lain terdapat paling tidak satu fungsi basis yang memuat variabel prediktor yang berpengaruh terhadap variabel respon.

Uji yang dilakukan secara individual terhadap setiap fungsi basis menggunakan hipotesis sebgai berikut :

$H_{0}: \alpha_{j}=0$ vs $H_{1} \alpha_{j} \neq 0$

dengan $\mathrm{j}=3,5,7,8,9,10,11,15,18,21,22,23,24,25,27,29,31$ dan 35 .

Dalam pengujian ini digunakan $\alpha=0.05$ sehingga $t_{(}(0,025 ; 181)=1,96$.

Karena untuk semua fungsi basis diperoleh $t_{\text {hitung }}>1,96$ maka diputuskan untuk tolak $H_{0}$ yang berarti bahwa semua fungsi basis yang terpilih dalam model MARS memiliki pengaruh terhadap variabel respon.

Tingkat kepentingan variabel prediktor pada MARS ditaksir dari perubahan nilai GCV yang disebabkan oleh perpindahan variabel-variabel diatas.Urutan variabel yang berkontribusi terhadap model MARS adalah FFMC, hari, temperatur, DMC, kelembaban relatif, bulan, koordinat sumbu y spasial suatu lokasi dalam peta, DC,dan koordinat sumbu $x$ spasial suatu lokasi dalam peta dengan tingkat kepentingan berturut-turut 100\%, 90.9\%, 73.5\%, 34.5\%, 25,1\%,23.1\%, $19.6 \%, 17.9 \%$ dan $5.7 \%$.

\section{Kesimpulan}

Berdasarkan penelitian yang telah dilakukan diperoleh nilai $R^{2}=0.958$ yang berarti variabel prediktor yang berkontribusi dalam model MARS dapat menjelaskan keragaman variabel respon dalam penelitian ini yaitu luas area kebakaran hutan sebesar 95.8\%. Dari 12 variabel prediktor yang diteliti pada penelitian ini ternyata hanya 9 variabel prediktor yang berkontribusi terhadap model MARS, yaitu FFMC, hari, temperatur, DMC, kelembaban relatif, bulan, koordinat sumbu $y$ spasial suatu lokasi dalam peta, DC, dan koordinat sumbu $x$ spasial suatu lokasi dalam peta. 


\section{Ucapan Terima kasih}

Penulis mengucapkan terima kasih kepada Bapak Dodi Devianto, Bapak Zulakmal dan Bapak Narwen yang telah memberikan masukan dan saran sehingga makalah ini dapat diselesaikan dengan baik.

\section{Daftar Pustaka}

1. Anonymous. 2012. Forest Fire. http://www.dsi.uminho.pt/ pcortez/fires. Diakses pada 2 Februari 2012

2. Anonim. 2001. MARSTM User Guide. Salford Systems, Inc. www.salfordsystems.com. Diakses pada 2 Februari 2012

3. Beck, J.A. 2002. Forcasting Diurnal Variations In Fire Intensity to Enhance Wildland Fire Fighter Safety. Compiler and Editor, Flannigan

4. Friedman, J.H. 1991. Multivariate Adaptive Regression Splines. The Annals of Statistics $19: 1-67$

5. Zhang. H and B.H. Singer. 2010. Recursive partitioning and Applications ed.2th. Springer, New York 